\title{
Radio induced cancer risk during ERCP. Is it a real clinical problem?
}

\author{
Manuel Luis Rodríguez-Perálvarez¹, Jose Antonio Miñano-Herrrero², Antonio José Hervás-Molina',

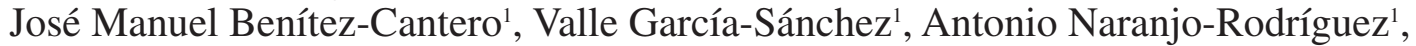 \\ María Pleguezuelo-Navarro ${ }^{1}$, María del Mar Soler-Cantos² and Manuel de la Mata-García
}

Departments of ${ }^{1}$ Digestive Diseases and ${ }^{2}$ Medical Physics. Hospital Universitario Reina Sofía. Córdoba, Spain

\begin{abstract}
Background: in recent years many factors have been shown to influence dose received by the patient during $\mathrm{ERCP}$. Therefore it is necessary to update radio induced cancer risk.

Objectives: to calculate lifetime attributable risk of cancer during ERCP. To compare the risk with the most common X-ray examinations.

Design: descriptive study with 393 consecutive ERCP performed at one center. Equipment used was Philips BV pulsera. In each exploration demographic and anthropometric variables of the patient were collected. Dosimetric quantities were calculated from exposure parameters. Effective dose was estimated using specific conversion factors. Organ doses and radio induced cancer incidence was estimated.
\end{abstract}

Results: dose area product was $0.82 \mathrm{mGym}^{2}$ (IQR 0.4-1.5) with an average fluoroscopy time of 2 minutes and 45 seconds. Entrance surface dose was $30.7 \mathrm{mGy}$ (IQR 15-60.8) and effective dose was $0.44 \mathrm{mSv}$ (IQR 0.2-0.9). Multivariate analysis identified that difficult papillary cannulation $(\beta 0.4 ; p=0.009)$, patient age $(\beta-0.01 ; p=0.001)$ and therapeutic applied $(\beta=0.89 ; p<0.001)$ influenced dose-area product. The ERCP dose would be equivalent to the radiation received by twenty chest radiographs and would be about fourteen times smaller than a barium enema or twenty times less than that received during an abdominal CT. Lifetime attributable risk of cancer incidence was 4.08 and 16.81 per million procedures in diagnostic and therapeutic ERCP respectively.

Conclusions: from the radiological point of view, ERCP is a safe technique that uses low exposure levels compared to other explorations commonly used in medicine. It implies a reasonably low risk of radio induced cancer.

Key words: ERCP. Radio induced cancer. Radiation doses. Effective dose. Dose area product.

Received: 02-11-10.

Accepted: 16-02-11.

Correspondence: Manuel Luis Rodríguez Perálvarez. Department of Digestive Diseases. Hospital Universitario Reina Sofía. Avda. Menéndez Pidal, s/n. 14014 Córdoba, Spain

e-mail: ropeml@hotmail.com
Rodríguez-Perálvarez Manuel Luis, Miñano-Herrrero Jose Antonio, Hervás-Molina Antonio José, Benítez-Cantero José Manuel, García-Sánchez Valle, Naranjo-Rodríguez Antonio, PleguezueloNavarro María, Soler-Cantos María del Mar, de la Mata-García Manuel. Radio induced cancer risk during ercp. Is it a real clinical problem? Rev Esp Enferm Dig 2011; 103: 191-195.

\section{BACKGROUND}

In recent years we have witnessed a significant development of radiological techniques applied to medicine which could mean an increase in radiation exposure for patients. However in ERCP, since the first studies were published more than 30 years ago (1), parallel development of new technologies has allowed us to minimize the radiation dose used and improve the quality of image obtained.

Several factors have been shown to influence the dose received by the patient during this technique. In this sense, the most described is therapeutic indication that could increase the dose area product (DAP) three to four times $(2,3)$. Therapeutic options are becoming more com- 
plex and require increased fluoroscopy time and thus increased patient dose (4). However, other factors like endoscopist experience (5) and time limited fluoroscopy (6) have been reported as able to shorten the fluoroscopy time.

Furthermore, previous studies have suggested that ERCP is safe from the radiological point of view, even in special situations such as pregnancy (7), although a recent study has questioned this assertion by detecting that occasionally exceeding the maximum recommended doses to the fetus (8), especially during the early pregnancy stage. For this reason, in high-risk situations like pregnancy, the priority is to minimize the dose and some authors have reported cases in which fluoroscopy was not needed $(9,10)$.

Considering the factors described above, it is possible that dose received by patient during ERCP has changed in recent years so it is necessary to update it with a large number of patients who can encompass all the current clinical possibilities. This study will reveal the actual risk involved in the radiation used during ERCP. This information may help in the future to minimize risks. The aims of the present study were: a) to estimate patient lifetime attributable risk of cancer incidence during ERCP; and b) to compare the risk with the most common X-ray examinations.

\section{METHODS}

This is an observational, descriptive, transversal study with 393 consecutive ERCP performed on 348 patients in one single center between February and September 2009. Explorations were carried out by three different endoscopists assisted by a fellow. All of them were blinded to the study. Experience in ERCP was very homogeneous between participating endoscopists. The number of procedures performed by each endoscopist ranged from 156 to 228 per year with all of them having more than ten years experience. In each exploration, demographic (gender and age) and anthropometric variables (weight, height and thickness) of the patient were registered. We also collected diagnostic or therapeutic intention of the exploration, number of cannulation attempts and treatment applied. Radiological parameters were provided by the equipment (fluoroscopy time, kilovoltage, miliamperaje and DAP).

From technique parameters, organ dose and effective dose have been calculated using normalized organ dose data published by the National Radiological Protection Board (NRPB) (11) and weighting factors given by International Commission on Radiological Protection (ICRP) (12). These parameters are crucial to estimate risks and compare with other radiological explorations.

The adult risk coefficients for cancer incidence from BEIR VII (13) were applied to calculate sex- and agespecific whole risk.

\section{Technical aspects}

The fluoroscopy X-ray unit used during the ERCP examinations was Philips BV Pulsera (Philips Medical Systems, Best, The Netherlands) with high frequency generator. The X-ray tube has a standard filtration of $3 \mathrm{~mm}$ aluminum and additional filtration of $0.1 \mathrm{~mm}$ copper. The system offers various continuous and pulsed fluoroscopy modes with different dose levels. In all explorations, the mode used was low dose at 12.5 pulses/second. Verification tests were conducted to assess the accuracy of displayed values of peak tube potential $(\mathrm{kVp})$, milliamps and time. The $\mathrm{kVp}$ and time measurements were made using a PMX III multimeter (RTI Electronics $\mathrm{AB}$, Sweden). The tube output was measured using a 2026C electrometer connected to a model 20X5-3 ionization chamber, both manufactured by Radcal Corporation (Radcal, Monrovia, CA). The system has calibration which is traceable to a national standard. The tube output linearity at $80 \mathrm{kVp}$ for a wide range of tube charge settings (3-100 mAs) was about $2 \%$. The radiation spectra were characterized by the total filtration and $\mathrm{kVp}$. With the PMX III mutimeter the half value layer was determined. From this measurement, the total filtration is determined using the conversion tables in the application note of RTI electronics. The X-ray unit had a DAP calculation system which was calibrated versus a Vacutec DAP meter (type 701159 C).

\section{Statistical analysis}

The sample size required should be sufficient to cover all current therapeutic options offered by the ERCP. To do this we take as reference a recent article performed by Kim et al. (4) that evaluated the clinical determinants on fluoroscopy time. In this study the minimum sample size estimated was 117 patients but finally included 388 scans. Our sample size was 393 explorations and we checked using EPIDAT 3.1 that it was sufficient to provide a statistical power of 0.9 and $\alpha$ error of 0.05 .

Statistical analysis was performed using SPSS 15.0 for Windows. First we achieved a descriptive study of variables. Quantitative variables are expressed like mean and standard deviation except radiological dose variables that are presented as median and interquartile range (IQR) because of its positive asymmetry. In the posterior analytical phase we applied appropriate hypothesis contrast tests. Finally, multivariate analysis was performed using multiple linear regression to establish those factors independently related with the radiological dose received by the patient and also to monitor possible confounding factors. The model had an associative character and the dependent variable used was DAP. All hypothesis tests were bilateral and considered statistically significant at $p<$ 0.05 . 
Table I. Descriptive study of variables

\begin{tabular}{|c|c|c|}
\hline \multirow[t]{2}{*}{ Variables } & \multicolumn{2}{|c|}{ Descriptive values } \\
\hline & itative (mean+/-SD) & Qualitative (n) (\%) \\
\hline Age & $75 \pm 12.34$ years & \\
\hline \multirow[t]{2}{*}{ Sex } & Men $211(53.7 \%)$ & \\
\hline & Women 182 & \\
\hline Weight & $69.52 \pm 12.73 \mathrm{~kg}$ & \\
\hline Height & $1.60 \pm 0.09 \mathrm{~m}$ & \\
\hline Thickness & $29.62 \pm 4.1 \mathrm{~cm}$ & \\
\hline \multirow[t]{5}{*}{ Technique } & Diagnostic 52 (13 & \\
\hline & Therapeutic 340 & $8 \%)$ \\
\hline & - Only sphincter & omy 102 (26\%) \\
\hline & $\begin{array}{l}\text { - Sphincterotom } \\
159(40.6 \%)\end{array}$ & + stone removal \\
\hline & - Stent placeme & or removal 79 \\
\hline \multirow[t]{3}{*}{ Cannulation attempts } & Less than five 307 & $8.4 \%)$ \\
\hline & Six to fifteen 51 & $6 \%)$ \\
\hline & More than sixteen & $(9 \%)$ \\
\hline \multirow[t]{3}{*}{ Complications } & Pancreatitis 10 (2. & \\
\hline & Gastrointestinal b & $\operatorname{ding} 9(2.3 \%)$ \\
\hline & Duodenal perfora & $2(0.5 \%)$ \\
\hline Mortality & $3(0.8 \%)$ & \\
\hline
\end{tabular}

\section{RESULTS}

We analyzed 393 ERCP performed at our hospital during the above period. Descriptive study is summarizing in table I. Kilovoltage and miliamperaje means were 80.25 $\mathrm{Kv}$ and $4.15 \mathrm{~mA}$ respectively. The average fluoroscopy time was two minutes and forty-five second being the DAP median $0.82 \mathrm{mGym}^{2}$ (IQR 0.4-1.5). ESD median was $30.7 \mathrm{mGy}$ (IQR 15-60.8) and effective dose was 0.44 $\mathrm{mSv}$ (IQR 0.2-0.9).

As in previous studies, we observed a positive linear correlation between fluoroscopy time and DAP. Although this relationship was strong and statistically significant ( $\mathrm{r}$ $=0.728 ; \mathrm{p}<0.001$ ), it was not perfect so we made a multiple linear regression analysis to establish what other factors may modify the DAP. In this analysis, therapeutic intention, papillary cannulation difficulty (need of six or more attempts) and younger patients demonstrated an independent association with higher DAP (Table II).

Examining the first point, diagnostic technique involved a DAP median of $0.3 \mathrm{mGym}^{2}$ (IQR $0.05-0.7$ ) while the therapeutic technique median was $0.94 \mathrm{mGym}^{2}$ (IQR 0.51.7) $(\mathrm{p}<0.001)$. Within the latter group, sphincterotomy alone involved a DAP of $0.54 \mathrm{mGym}^{2}$ (IQR 0.37-1.04) while combining sphincterotomy with stone extraction implied a median of $0.89 \mathrm{mGym}^{2}$ (IQR 0.84-1.56). In the group of stent placement or removal the median was 1.66 mGym $^{2}$ (IQR 1.1-2.74) with significant differences with previous two groups ( $\mathrm{p}<0.001$ in both cases) (Fig. 1). With the fluoroscopy time, something similar to the above
Table II. Multiple linear regression

\begin{tabular}{lcll}
\hline Variable & $\beta$ coefficient & $\begin{array}{l}\text { Confidence } \\
\text { interval 95\% }\end{array}$ & $p$ \\
\hline $\begin{array}{l}\text { Therapeutic intention } \\
\text { Cannulation difficulty }\end{array}$ & 0.89 & $0.52-1.27$ & $<0.001$ \\
$\begin{array}{l}\text { ( } 5 \text { or } \geq 6 \text { attempts) } \\
\text { Patient age }\end{array}$ & 0.40 & $0.10-0.70$ & 0.009 \\
& -0.17 & $-0,26-(-0,07)$ & 0.001 \\
\hline
\end{tabular}

Coefficient of determination $R^{2}=0.15 ; F=-1,15 ; G L=5 ; p=0,483$.

happens. The sphincterotomy group introduced an average time of 1 minute and 48 seconds while in the sphincterotomy with stone extraction group was 2 minutes 50 seconds $(\mathrm{p}=0.004)$. The stent placement or removal group implied an average fluoroscopy time of 5 minutes and 5 seconds ( $\mathrm{p}$ $<0.001$ with both previous). All this suggests that the higher the technique complexity, especially when it involves the placement of biliary stents, a higher fluoroscopy time is needed entailing an increase of DAP to the patient.

Papillary cannulation difficulty, measured by the number of attempts necessary to inject contrast in the biliary conduct, influenced DAP in multivariate analysis ( $\mathrm{p}=$ 0.009). In this sense, the group of less than five attempts produced a DAP median of $0.81 \mathrm{mGym}^{2}$ (IQR 0.45-1.43) while the group with six or more attempts produced 1.07 mGym $^{2}$ (IQR 0.34-1.96).

Younger patients had higher DAP so that a 10 -year increase in the patient's age meant a decline of $0.17 \mathrm{mGym}^{2}$ in DAP. In order to find the reason for this curious relationship, we separated patients into two groups according to their age. We found that patients younger than 65 years had a higher proportion of stent placement than patients older than 65 years ( 37.5 and $15.1 \%$ respectively; $\mathrm{p}<0.001)$. No other variables significantly influenced the DAP.

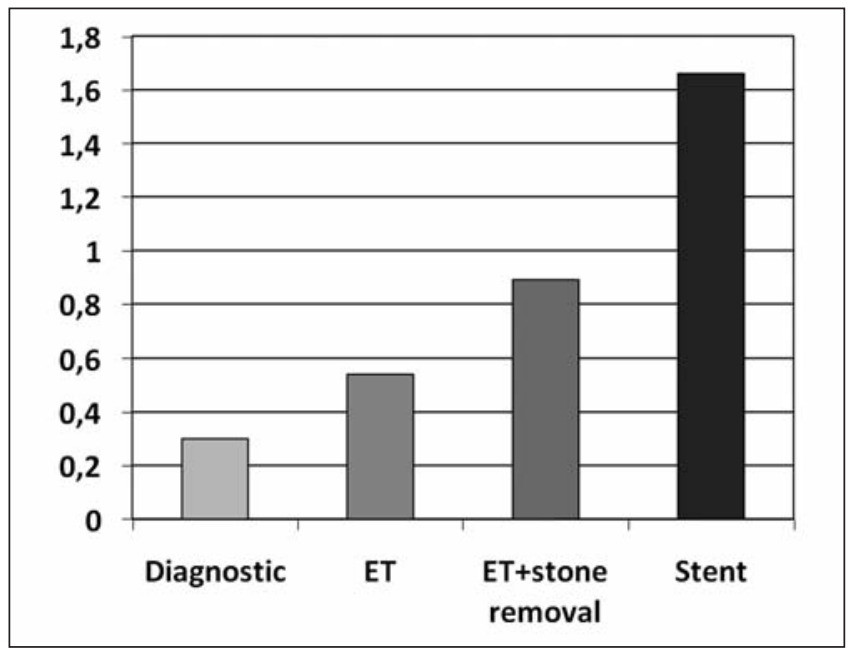

Fig. 1. Therapeutic and DAP. Higher technique complexity implies higher DAP ( $p<0.001$ in all comparisons). 
Table III. Organ dose median (mGy) and lifetime attributable cancer incidence (per 1 million explorations). Calculated for 75 years old

\begin{tabular}{|c|c|c|c|c|}
\hline \multirow[t]{2}{*}{ Organ } & \multicolumn{2}{|c|}{ Diagnostic ERCP } & \multicolumn{2}{|c|}{ Therapeutic ERCP } \\
\hline & Dose (mGy) & Cancer (per million ERCP) & Dose (mGy) & Cancer (per million ERCP) \\
\hline Adrenal gland & 0.048 & 0.0160 & 0.225 & 0.0745 \\
\hline Breast & 0.008 & $0.0096 *$ & 0.037 & $0.0296 *$ \\
\hline Gallbladder & 0.509 & 0.1686 & 2.339 & 0.7749 \\
\hline Stomach & 0.042 & 0.0535 & 0.209 & 0.2664 \\
\hline Small bowel & 0.010 & 0.0132 & 0.097 & 0.0321 \\
\hline Colon & 0.174 & 0.6205 & 0.801 & 0.3264 \\
\hline Heart & 0.019 & 0.0062 & 0.093 & 0.0308 \\
\hline Kidney & 0.069 & 0.0228 & 0.321 & 0.1063 \\
\hline Liver & 1.018 & 0.4581 & 4.628 & 2.0826 \\
\hline Lung & 0.023 & 0.1857 & 0.108 & 0.8721 \\
\hline Ovary & 0.012 & $0.0096^{*}$ & 0.063 & $0.0504^{*}$ \\
\hline Pancreas & 0.102 & 0.0337 & 0.472 & 0.1563 \\
\hline Skin & 17.10 & 2,3176 & 32.82 & 10.87 \\
\hline Spleen & 0.011 & 0.0036 & 0.066 & 0.0218 \\
\hline Thymus & 0.003 & 0.0001 & 0.019 & 0.0062 \\
\hline Bladder & 0.002 & 0.007 & 0.014 & 0.0493 \\
\hline Esophagus & 0.011 & 0.0036 & 0.059 & 0.0195 \\
\hline Uterus & 0.009 & $0.0126^{*}$ & 0.050 & $0.0175^{*}$ \\
\hline Bone marrow & 0.025 & 0.1306 & 0.115 & 0.6008 \\
\hline Brain, eye lens and testicles & 0 & 0 & 0 & 0 \\
\hline Residual tissues & 0.047 & 0.0155 & 0.214 & 0.1418 \\
\hline Total & & 4.08 & & 16.81 \\
\hline
\end{tabular}

*Applicable for female only.

Effective dose was calculated to estimate risk for patients. In diagnostic explorations, the effective dose median was $0.11 \mathrm{mSv}$ (IQR 0.02-0.5) while in the therapeutic ones it was $0.49 \mathrm{mSv}$ (IQR 0.25-0.94).

Organ doses and lifetime radio induced fatal cancer for each organ are shown in table III. Therapeutic explorations registered higher organ dose. Notice that the highest doses were registered by organs situated closer to the bile duct like the liver (1.61 and $4.62 \mathrm{mGy}$ for diagnostic and therapeutic ERCP respectively) and the gallbladder $(0.115$ and 0.530 mGy for diagnostic and therapeutic ERCP respectively). Using an average patient age of 75 years old (based on the present study results), we obtained a lifetime risk of radio induced cancer of 4.08 per million diagnostic explorations. In therapeutic ERCP 16.81 radio induced cancer per million explorations was estimated. Finally, with the aim of extending the results of this study to other younger populations, we estimated the risk for patients with a mean of 60 years yielding a value of 7.68 and 31.64 per million explorations for diagnostic and therapeutic ERCP respectively.

\section{DISCUSSION}

Over the last few years, dose received by patients during ERCP have declined dramatically. The first high quality study published on this topic was conducted by Larkin et al. (2). They included 20 procedures and found an average DAP of 1.35 and $6.68 \mathrm{mGym}^{2}$ for diagnostic and therapeutic ERCP respectively. Three years later Bambrilla et al. (14) reported reference dose levels for various radiologic techniques including ERCP with a DAP mean of 3.3 $\mathrm{mGym}^{2}$. In the present work, DAP was $0.54 \mathrm{mGym}^{2}$ for diagnostic ERCP and $1.31 \mathrm{mGym}^{2}$ for therapeutic ERCP, values much lower than those referred to above.

Thus, the technological development of more modern equipment that includes modes with low radiation and high imaging quality has played a key role. However, this was not the only factor involved. Fluoroscopy time has halved in diagnostic tests and even more for therapeutic explorations. This may be because endoscopists have more experience in this technique nowadays. In our study, endoscopists experience was assessed. According to the rules published in a recent study (5), the experience of the endoscopists participating in this study was medium-high. We found no differences in fluoroscopy time or DAP between endoscopists.

The results obtained allowed us to compare the risk of radiation-induced cancer in ERCP with other radiological techniques commonly used in medicine. Using data obtained from the European Commission of radiological protection (15), the effective dose found in this study, 
would place ERCP in band I (Table IV). The ERCP dose would be equivalent to the radiation received by twenty chest radiographs and would be about fourteen times smaller than a barium enema or twenty times less than that received during an abdominal CT.

In our multiple linear regression model we found that the conduct of therapy, especially the placement of biliary stent, implied a higher DAP. This has already been reported in many previous studies $(2-4,8)$ showing that therapeutic ERCP could be six times higher. In fact, in most studies regarding radiation dose, authors differentiate between diagnosis and therapeutic ERCP, treating them as two different techniques. Difficult papillary cannulation has emerged as another factor that can increase the DAP independently. A previous study (6) showed that this fact implies a prolonged fluoroscopy time but did not confirmed an influence in DAP.

Younger patients registered a higher DAP in the present study. This fact has not been previously described and has a very difficult explanation itself. Probably it could be justified by the high proportion of biliary stent placement registered in less than sixty five years old patients in our series as we revealed above. This fact can justify that, younger patients also had longer fluoroscopy time (146.3 and 213.6 seconds respectively; $p=0.012$ ).

Finally we would like to emphasize that the fit goodness of the model (R2) was 0.15 implying that only $15 \%$ of the variability of DAP is explained by the variables commented previously. This suggests that there are many other factors involved in the radiation dose received by the patient during ERCP. One of these factors (probably the most important) is fluoroscopy time that was not included in the model because the strong correlation with DAP showed, that it could interfere with the other variables. We cannot discard the existence of other variables, especially those related to the equipment $\mathrm{s}$ automatic adjustments, that may affect DAP.

Lifetime radio induced cancer incidence was obtained using effective dose and specific organ doses. We calculated 1 fatal cancer per three hundred thousand explorations in diagnostic ERCP and 1 fatal cancer per fifty thousand explorations in therapeutic ERCP approximately. These values are much lower than previously described (2). The most important factor implied in that reduction is lower dose registered. Nevertheless, the aging of the population under this procedure has played a key role. In fact, we showed that, considering a 60 years old population (fifteen years younger than ours), lifetime radio induced cancer risk during ERCP became twice, however it remains low.

We can summarize that the dose received during ERCP has decreased considerably in recent years and may nowadays be regarded as a safe imaging technique compared to other radiological explorations commonly used in medicine. Clinical aspects such as difficult papillary cannulation or more complex therapeutic (especially when biliary stent is placed) can prolong the fluoroscopy time and increase the dose received by the patient. Radio induced can-
Table IV. Band classification of the typical effective doses of ionizing radiation from common imaging procedures (adapted from reference 15)

\begin{tabular}{|c|c|c|}
\hline Band & $\begin{array}{l}\text { Typical effective } \\
\text { dose (mSv) }\end{array}$ & Examples \\
\hline 0 & 0 & $\begin{array}{l}\text { Ultrasonography, magnetic } \\
\text { resonance imaging }\end{array}$ \\
\hline । & $<1$ & $\begin{array}{l}\text { Conventional X-ray thorax, limb, } \\
\text { pelvis }\end{array}$ \\
\hline$\|$ & $1-5$ & $\begin{array}{l}\text { Conventional X-ray pelvis, CT head } \\
\text { and neck, intravenous urogram }\end{array}$ \\
\hline III & $5-10$ & $\begin{array}{l}\text { CT chest and abdomen, cardiac } \\
\text { nuclear medicine }\end{array}$ \\
\hline IV & $>10$ & Some PET \\
\hline
\end{tabular}

CT: computed tomography; PET: positron emission tomography.

cer risk is reasonably low but is expected to fall further in the coming years with the advent of new technologies and the participation of more experienced endoscopists.

\section{REFERENCES}

1. Cohen G, Brodmerkel GJ, Lynn S. Absorbed doses to patients and personnel from endoscopic retrograde cholangiopancreatographic (ERCP) examinations. Radiology 1979;130(3):773-5.

2. Larkin C, Workman A, Wright R, Tham T. Radiation doses to patients during ERCP. Gastrointest Endosc 2001;53(2):161-4.

3. Olgar T, Bor D, Berkmen G, Yazar T. Patient and staff doses for some complex X-ray examinations. J Radiol Prot 2009;29(3):393-407.

4. Kim E, McLoughlin M, Lam EC, Amar J, Byrne M, Telford J, et al. Prospective analysis of fluoroscopy duration during ERCP: critical determinants. Gastrointest Endosc 2010;72(1):50-7.

5. Jorgensen J, Rubenstein J, Goodsitt M, Elta GH. Radiation doses to ERCP patients are significantly lower with experienced endoscopists. Gastrointest Endosc 2010;72(1):58-65.

6. Uradomo L, Goldberg E, Darwin P. Time-limited fluoroscopy to reduce radiation exposure during ERCP. Gastrointest Endosc 2007;66:84-9.

7. Kahaleh M, Hartwell G, Arseneau K,Pajewski TN, Mullick T, Isin G, et al. Safety and efficacy of ERCP in pregnancy. Gastrointest Endosc 2004;60(2):287-92.

8. Samara ET, Stratakis J, Enele Melono JM, Mouzas IA, Perisinakis K, Damilakis J. Therapeutic ERCP and pregnancy: is the radiation risk for the conceptus trivial? Gastrointest Endosc 2009;69(4):824-31.

9. García-Cano J, Palomo Sánchez JC, Gómez Ruiz CJ. CPRE sin utilización de fluoroscopia en una paciente gestante con coledocolitiasis. Rev Esp Enferm Dig 2008;100(2):100-1.

10. Akcakaya A, Veli Ozkan O, Okan I, Kocaman O, Sahin M. Endoscopic retrograde cholangiopancreatography during pregnancy without radiation. World J Gastroenterol 2009;15(29):3649-52.

11. Hart D, Jones DG, Wall BF. Normalized organ doses for medical Xray examinations calculated using Montecarlo techniques. NRPBSR262. National Radiological Protection Board: 1994.

12. Beninson D. 1990 Recommendations of the International Commission on Radiation Protection. Oxford: Pergamon; 1991.

13. Monson R. Health risks from exposure to low levels of ionizing radiation-BEIR VII. National Research Council. The National Academies Press; 2005.

14. Bambrilla M, Marano G, Dominietto M, Cotroneo AR, Carriero A. Patient radiation doses and references levels in interventional radiology. Radiol Med 2004;107(4):408-18.

15. Needham G, Grimshaw J. Referral Guidelines for Imaging. European commission on radiological protection (update Mars 2008). 